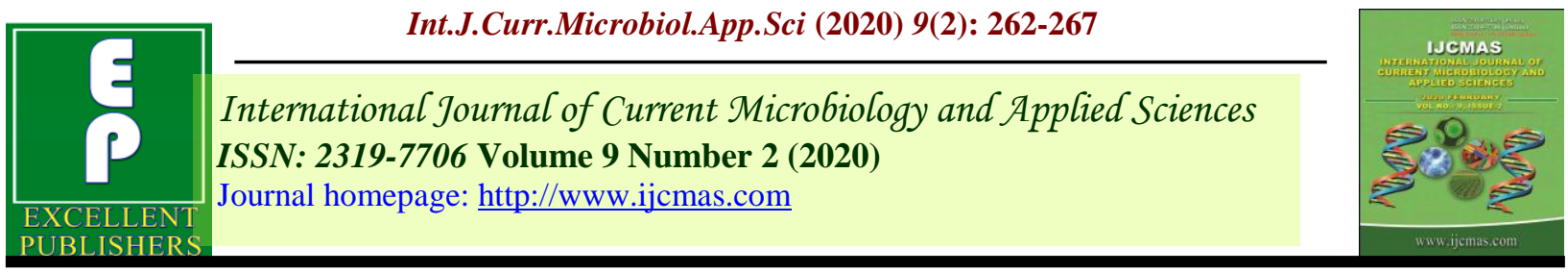

Original Research Article

https://doi.org/10.20546/ijcmas.2020.902.033

\title{
Impact of Malting on Antioxidant Content and DPPH Scavenging Activity of Medicago sativa
}

\author{
Sakshi Pandey ${ }^{1 *}$, Neelam Chaturvedi ${ }^{2}$ and Diksha Gupta ${ }^{2}$ \\ ${ }^{1}$ Jayoti Vidyapith Women's University, Rajasthan, India \\ ${ }^{2}$ Department of Food Science and Nutrition, Banasthali Vidyapith, \\ Dist-Tonk, Rajasthan, India \\ *Corresponding author
}

\section{Keywords}

Medicago sativa,

Total phenols

content, Total

flavonoids content, DPPH

Article Info

Accepted:

05 January 2020

Available Online:

10 February 2020

A B S T R A C T

Medicago sativa is well- known medicinal herb found in India that have high amount of bioactive components which attribute to a strong free radical scavenging activity. In view of the above aspects the present work was undertaken to study the antioxidant potential (total phenols, total flavonoids and ascorbic acid content as well as DPPH scavenging activity) of unmalted and malted seeds with slight modification of standard methods. The study revealed that showed that malted seeds had significantly higher content of total phenols $(41.8 \pm 0.09 \mathrm{mgGAE} / \mathrm{g})$, total flavonoids $(13.5 \pm 0.02 \mathrm{mgQE} / \mathrm{g})$ and ascorbic acid content $(8.5 \pm 0.05)$ as compared to unmalted seeds which was significantly increased by $17.7 \%, 16.3 \%$ and $15.9 \%$ at $\mathrm{p}<0.05$ level. Whereas, malted seeds exhibits highest antioxidant activity with $\mathrm{IC}_{50}$ value $(70.1 \mu \mathrm{g} / \mathrm{ml})$ followed by unmalted seeds $(86.7 \mu \mathrm{g} / \mathrm{ml})$. Thus, it is concluded that malting as a processing could be used effectively to enhance the antioxidant potential of seeds.

\section{Introduction}

Legumes play an important role in the mostly vegetarian diet of the Indian population and are consumed regularly in every household at least in one meal (Gujral et al., 2013). India is the largest consumer and importer of pulses in the world. They contain good amount of carbohydrates, proteins, fibres and bioactive compounds such as phenols, flavonoids phytosterols, lignans and many other components. These components are associated with lowering the risk of metabolic disorders i.e. type II diabetes, cardiovascular, cancer and many other diseases (Pudnez, et al., 2014). They are also supposed to possess antioxidative, anti-inflammatory, antiallergic and anticarcinogenic activities due to high 
concentration of phenolic compounds (Nderitu, et al., 2013).

Medicago sativa commonly known as alfalfa is a perennial species belongs to the leguminosae family. It is one of the genus and most reputed medicinal plants which has the largest cultivation area because of its numerous qualities such as cold resistance, salt tolerance, high yield, soil amelioration and economic benefits (Shangli et al., 2017).

It is considered as 'father of all plants' and green food of the millennium and one of the remarkable legumes that contain high amount of protein, calcium, vitamins in order to maintain proper functioning of the whole body (Dong et al., 2011). It also contains high amount of pharmacologically active components including acids (lauric, maleic, malic, malonic, myristic, oxalic, palmitic, quinic), saponins, alkaloids, flavonoids, glycosides, phytoestrogen and phenols with various pharmacological properties such as antimicrobial, anti-inflammatory, anticancer, antihypercholesterolemic and antidiabetic (Rathee et al., 2009).

Several methods have been generally adopted to improve the nutritional and organoleptic qualities of legumes. Malting has been suggested as an inexpensive and effective way to improve the quality of legumes and for the elimination of the nutritional impediments of foods. It is a biotechnological technique which involves the controlled germination of a cereal grain (Laxmi et al., 2015) by which the quality of a cereal can be improved for both digestibility and physiological function, particularly through the breakdown of certain anti- nutrients, such as phytate, tannin and protease inhibitors (Graham et al., 2000). In this regard, the main objective of the present research is to study the impact of malting on antioxidant potential of Medicago sativa.

\section{Materials and Methods}

\section{Collection of seeds}

Medicago sativa (alfalfa) were purchased from the local market of Haldwani and authenticated by Agronomic and Horticulture Department of GB Pant University of Uttarakhand. The flour was prepared by malting technique which includes Soaking (3h), Germination (48h) and Kilning (4h).

\section{Preparation of malted flour}

$500 \mathrm{~g}$ of seeds were weighed, stored and steeped in distilled water for $3 \mathrm{~h}$ at room temperature and rained seeds were spread on a moistened jute sack and allowed to germinate at room temperature (2 days).

The germinated grains were manually washed with distilled water, drained and kilning was done at $60^{\circ} \mathrm{C}$ for $4 \mathrm{~h}$. The dried grains were milled using mixer grinder, sieved and put into airtight container under room temperature for further analysis.

\section{Preparation of aqueous extract}

$20 \mathrm{~g}$ of seeds powder was kept in $200 \mathrm{ml}$ conical flask and $100 \mathrm{ml}$ distilled water was added.

The mouth of the conical flask was covered with the aluminium foil and kept in a reciprocating shaker for 25 minutes for continuous agitation at $150 \mathrm{rpm}$ for thorough mixing. Then extracts were filtered by using muslin cloth followed by whatman filter paper No. 42 (125mm).

The contained was filtered by using rotator vacuum evaporator with the water bath temperature of $65^{\circ} \mathrm{C}$ and finally the residues were collected and used for the analysis (Nagappan, 2012). 


\section{Determination of antioxidants content}

\section{Determination of total phenols content}

Total phenols content were determined by Folin-Ciocalteu Reagent using gallic acid as a standard phenolic compound. A dilute extract of tuber $(0.5 \mathrm{ml}$ of $1: 10 \mathrm{~g} / \mathrm{ml})$ or Gallic acid was mixed with Folin-Ciocalteu reagent (5 $\mathrm{ml}, 1: 10$ diluted with distilled water) and the mixture was stirred vigorously. $4 \mathrm{ml}$ of aqueous sodium carbonate $(1 \mathrm{M})$ was added after 3 minutes and then allowed to stand for $2 \mathrm{~h}$ with intermittent shaking. After that, the absorbance was measured at $765 \mathrm{~nm}$ in spectrophotometer against blank consisting of all the reaction agents except the extract. Total phenols content values are expressed in terms of Gallic acid equivalent (mgGAE/g of dry mass) (McDonald et al., 2001).

\section{Determination of total flavonoids content}

Total flavonoids content were determined by using aluminium chloride colorimetric assay. A volume of $125 \mu 1$ of tuber extract is added to $75 \mu 1$ of a $5 \% \mathrm{NaNO}_{2}$ solution. The mixture was allowed to stand for $6 \mathrm{~min}$. $150 \mu \mathrm{l}$ of aluminium trichloride (10\%) was added in it and incubated for $5 \mathrm{~min}$, followed by the addition of $750 \mu \mathrm{l}$ of $\mathrm{NaOH}(1 \mathrm{M})$. The final volume of the solution was adjusted to $2500 \mu 1$ with distilled water. After $15 \mathrm{~min}$ of incubation of mixture turned to pink and the absorbance was measured at $510 \mathrm{~nm}$ using spectrophotometer. The total flavonoids content was expressed as $\mathrm{mg}$ of quercetin equivalent (mgQE/g dry mass) (Ebrahimzaded et al., 2008).

\section{DPPH radical scavenging activity}

The ability of the aqueous extracts to scavenge free radicals was determined against a very stable free radical DPPH $(2,2$ diphenyl-1-picrylhydrazyl) determined
Spectrometric method. Aliquots of the sample extract at different concentrations 20-200 $\mu \mathrm{g} / \mathrm{ml}$ were added to $1 \mathrm{~mm}$ aqueous solutions of DPPH. Each mixture was vortexes vigorously and left for $30 \mathrm{~min}$ at room temperature in the dark. The absorbance was measured at $517 \mathrm{~nm}$ and activity was expressed as percentage. $\mathrm{IC}_{50}$ value was also determined by graph (Nithianantham et al., 2008). DPPH scavenging relative to control using the following equation:

DPPH scavenging activity $(\%)=\frac{(\text { Absorbance of control }- \text { Absorbance o f sample) })}{\text { Absorbancce of control }}$ X100

\section{Statistical analysis}

The results obtained were expressed as Mean \pm SD and Paired t-Test of three determinations and also statistically analysed to ascertain its significance. The significance was estimated at ( $\mathrm{p} \leq 0.05$ level).

\section{Results and Discussion}

Table 1 showed that the total phenolic content (mgGAE/100g) and total flavonoids content $(\mathrm{mgQE} / 100 \mathrm{~g})$ of unmalted seeds aqueous extract were $35.5 \pm 0.02$ and $11.6 \pm 0.17$ respectively. Whereas, malted seeds extract had 11.6 \pm 0.17 and $13.5 \pm 0.02$ total phenol and flavonoids content which were significantly increased by $17.7 \%$ and $16.3 \%$ atp $\geq 0.05$ level when compared with unmalted seeds extract. Similar study was conducted by Aguilera et al., (2013) who reported that germinated seeds of Stizolobium niveum contained significantly higher total phenols content $(46.30 \pm 0.12 \mathrm{mgGAE} / 100 \mathrm{~g})$ when compared with ungerminated seeds $(37.40 \pm 0.42 \mathrm{mg}$ $\mathrm{GAE} / 100 \mathrm{~g}$ ) and significantly increased by $23.7 \%$ which is agreement with the obtained results. The value obtained compared favourably with Carciochi et al., (2016) who reported that malted seeds of quinoa had significantly higher total flavonoids content 
i.e. $17.65 \mathrm{mgQE} / 100 \mathrm{~g}$ when compared with unmalted seeds(11.06 $\mathrm{mg} \quad \mathrm{QE} / 100 \mathrm{~g})$ and significantly increased by $59.5 \%$ at $\mathrm{p} \geq 0.05$ level. The ascorbic acid content $(\mathrm{mg} / 100 \mathrm{~g})$ of unmalted and malted seeds extract was $3.81 \pm 0.16$ and $8.5 \pm 0.05$ respectively. This shows that ascorbic acid content of malted seeds was significantly increased by $15.9 \%$ at $\mathrm{p} \geq 0.05$ level when compared to unmalted seeds. The present study is comparable with Laxmi et al., 2015 who reported that malted chickpeas had significantly higher vitamin content i.e. $7.1 \mathrm{mg} / 100 \mathrm{~g}$ as compared to unmalted seeds $(3 \mathrm{mg} / 100 \mathrm{~g})$ which was significantly increased by $136.6 \%$ at $\mathrm{p} \geq 0.05$ level.

Table.1 Antioxidant Content of Aqueous Extract of Unmalted and Malted Medicago sativa

\begin{tabular}{|c|c|c|}
\hline \multirow{2}{*}{ Antioxidants } & \multicolumn{2}{|c|}{ Medicago sativa Extract } \\
\cline { 2 - 3 } & Unmalted & Malted \\
\hline $\begin{array}{c}\text { Total Phenols Content } \\
\text { (mgGAE/100g) }\end{array}$ & $35.5 \pm 0.0 .2$ & $41.8 \pm 0.09 *(17.7 \% \uparrow)$ \\
\hline $\begin{array}{c}\text { Total Flavonoids Content } \\
\text { (mgQE/100g) }\end{array}$ & $11.6 \pm 0.17$ & $13.5 \pm 0.02 *(16.3 \% \uparrow)$ \\
\hline $\begin{array}{c}\text { Ascorbic Acid } \\
\text { (mg/100g) }\end{array}$ & $3.81 \pm 0.16$ & $8.5 \pm 0.05 *(15.9 \% \uparrow)$ \\
\hline
\end{tabular}

Values are expressed as Mean \pm SD of triplicate determinations of unmalted and malted seeds flour.

*Shows significant difference at $(\mathrm{p} \geq 0.05)$ level at $(\mathrm{p} \geq 0.05)$ level

Figure.1 \% DPPH Radical Scavenging Activity of Aqueous Extract of Unmalted and Malted Medicago sativa

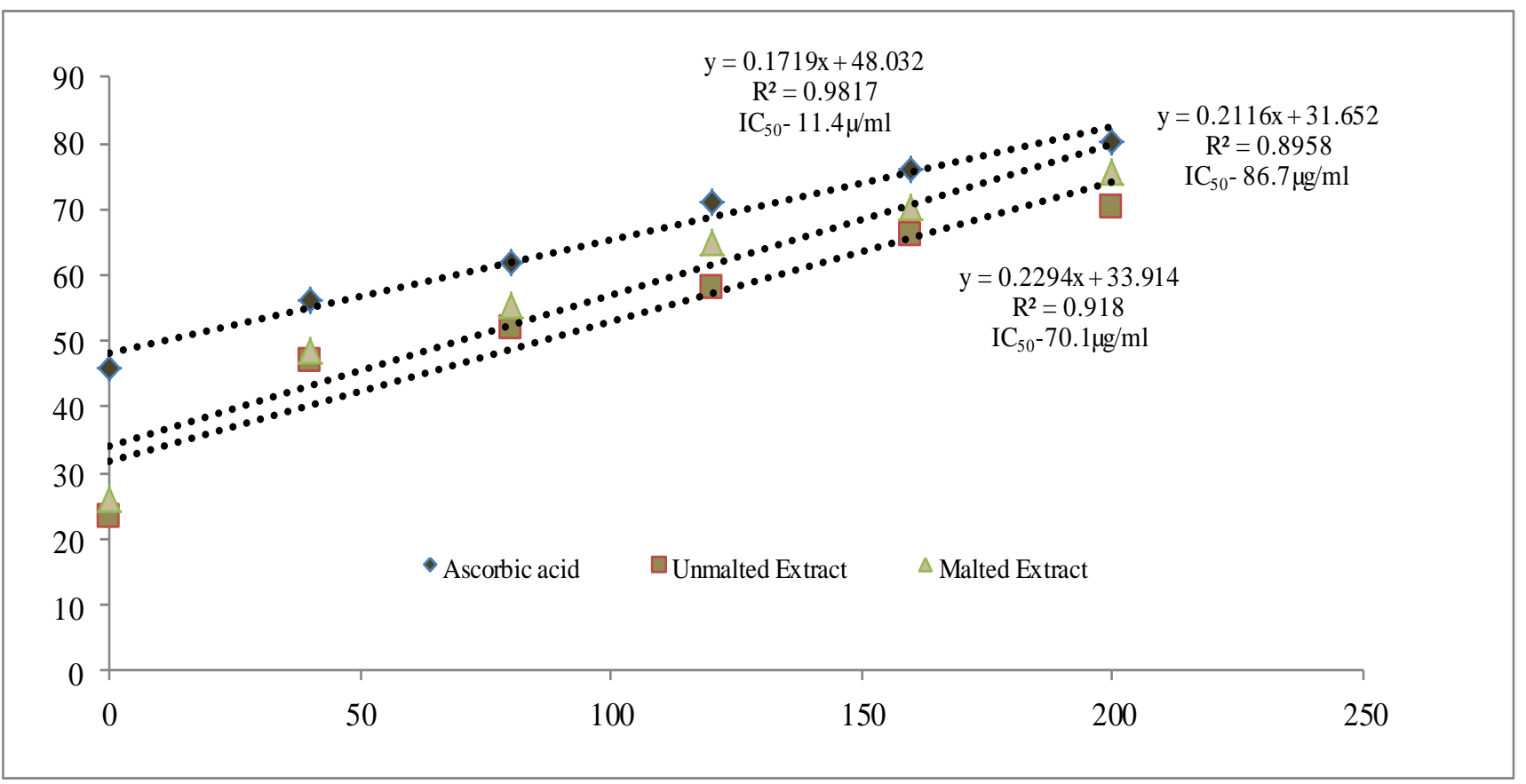


In vitro activities of both unmalted and malted seeds extracts were measured with the standard antioxidant (Ascorbic acid). Here, the DPPH free radical scavenging activities of unmalted and malted alfalfa seeds is shown in Figure 1. The malted seeds exhibits highest antioxidant activity with $\mathrm{IC}_{50}$ value $(70.1 \mu \mathrm{g} / \mathrm{ml})$ followed by unmalted seeds $(86.7 \mu \mathrm{g} / \mathrm{ml})$ as compared to control $(11.4 \mu \mathrm{g} / \mathrm{ml})$. Thus, aqueous extract of malted seeds showed strongest antioxidant activity as compared to unmalted alfalfa seeds extract. Similar study demonstrated by Gomathi et al., 2016 who reported that DPPH scavenging activities of raw and germinated alfalfa seeds extract with $\mathrm{IC}_{50}$ values were $61.9 \mu \mathrm{g} / \mathrm{ml}$ and $80.02 \mu \mathrm{g} / \mathrm{ml}$ respectively. Whereas, Simic et al., 2017 have revealed that DPPH scavenging activities of unmalted and malted barley grain extract with $\mathrm{IC}_{50}$ values were $62.2 \mu \mathrm{g} / \mathrm{ml}$ and $68.1 \mu \mathrm{g} / \mathrm{ml}$.

In conclusion, the study indicates that malting had significantly affected the total phenols, total flavonoids and ascorbic acid content as well as antioxidant activity of seeds. Thus, it might be concluded that malting as a processing can be used effectively to enhance the antioxidant potential of seeds.

\section{References}

1. Aguilera, Y., Diaz, F.M., Jimeenez, T., Benitez, V., Herrera, T., Cuadrado, C., Martin-Pedrosa, $\mathrm{M}$ and Martin-Cabrejas, A.M. 2013. Changes in Nonnutritional Factors and Antioxidant Activity during Germination of Nonconventional Legumes. Journal of Agriculture and Food Chemistry, 61:8120-8125

2. Carciochi, A.R., Dimitrov, $K$ and Dalessandro, G.L. 2016. Effect of malting conditions on phenolic content, Maillard reaction products formation, and antioxidant activity of quinoa seeds. Journal of Food Science and Technology,
53(11):3978-3985.

3. Duke, J.A. 2006. Hand book of medicinal herbs. India: CRS Press, 10-11.

4. Federico, F., Daniela, G., Velento, P., Goncalves, R., Pio, R., Chagas, E.A., Seabra, R.M., Andrabe, P.B., Rui, G., Rafael, P., Edvan, A.C., Rosa, M.S and Paula, B.A. 2009. Improved loquat (Eriobotrya japonica Lindl.) cultivars: Variation of phenolics and antioxidative potential. Journal of Agricultural food chemistry, 114(13):1019-1027.

5. Gomathi, R., Banu, S and Usha K. 2016. Phytochemical analysis and free radical scavenging potential of Medicago sativa Linn seeds. International Research Journal of Pharmacy, 7(6):71-76.

6. Gujral, S.H., Sharma, P., Gupta, N and Wani, A.A. 2013. Antioxidant properties of legumes and their morphological fractions as affected by cooking. Food Science and Biotechnology, 22(1):187194.

7. Joy, S.G and George, P. 2014. Antimicrobial screening of Alfalfa (Medicago sativa) in various bacterial strains. International Journal of Pharmaceutics and Drug Analysis, 2(1):65-69.

8. Laxmi, G., Chaturvedi, $\mathrm{N}$ and Richa, $\mathrm{S}$. 2015. The Impact of malting on nutritional composition of foxtail millet, wheat and chickpea. Journal of Nutrition and Food Sciences, 5:5.

9. McDonald, S., Prenzler, P.D., Antolovich, M and Robards, K. 2001. Phenolic content and antioxidant activity of olive extracts. Food Chemistry, 73(1):73-84.

10. Nagappan, R. 2012. Evaluation of aqueous and methnol extracts of bioactive medicinal plant, Cassia didymobotrya(Fresenius) Irwin \& barne by against immature stages of filarial vector, Culex quinquesfasciatus say (Diptera: Culiidae). Asian Pacific Journal 
of Tropical Biomedicine, 2:707-711.

11. Nderitu, A.M., Dykes, L., Awika, J.M., Minnaar, A and Duodu, K.G. 2013. Phenolic composition and inhibitory effect against oxidative DNA damage of cooked cowpeas as affected by simulated in vitro gastrointestinal digestion. Food Chemistry, 141:1763-1771.

12. Pudenz, M., Roth, K and Gerhauser, C. 2014. Impact of soy isoflavones on the epigenome in cancer prevention. Nutrients, 6:4218-4272.

13. Shiva, M., Mohammad, S., Manoochehr, H., Yaghoub, A and Seyed, E.S.E. 2007. Antioxidant power of Iranian propolis extract. Food Chemistry, 103:729-733.

14. Shukla, A., Tyagi, R., Vats, $S$ and Shukla, R.K. 2016. Total phenolic content, antioxidant activity and phytochemical screening of hydroalcoholic extract of Casearia tomentosa leaves. Journal of Chemical and Pharmaceutical Research, 8(1):136141.

15. Simic, G., Horvat, D., Dvojkovic,K., Abicic I., Vuletic, V.M., Tucak, $M$ and Lalic, A. 2017. Evaluation oftotal phenolic content and antioxidant activity of malting and hulless barley grain and malt extracts. Czech Journal of Food Sciences, 35(1):73-78.

16. Subhan, N., Alam, M.A., Ahmed, F., Awal, M.A., Nahar, L and Sarkar, S.D. 2008. In vitro antioxidant property of the extract of Excocaria agallocha. Journal of Pharmaceutical Sciences, 16(3):149154.

17. Sunggyy, L. 2005. Encyclopedia of chemical processing. Lee: CRC Press, 21:3640.

\section{How to cite this article:}

Sakshi Pandey, Neelam Chaturvedi and Diksha Gupta. 2020. Impact of Malting on Antioxidant Content and DPPH Scavenging Activity of Medicago sativa. Int.J.Curr.Microbiol.App.Sci. 9(02): 262-267. doi: https://doi.org/10.20546/ijcmas.2020.902.033 